\title{
UNA ESPECIE NUEVA DE TECTARIA (FILICALES: TECTARIACEAE) EN PANAMÁ
}

\author{
Alexander Fco. Rojas Alvarado \\ Jardín Botánico Lankester, Universidad de Costa Rica, apdo. 1031-7050, Cartago, Costa Rica. \\ afrojasa@yahoo.com
}

\begin{abstract}
Aвstract. Tectaria dressleri A. Rojas, presently known only from Panama, is described as a new species characterized by entire fronds, pilose blade and glabrous indusium.
\end{abstract}

Resumen. Tectaria dressleri A. Rojas, de Panamá, se describe como una especie nueva caracterizada por frondas enteras, lámina pilosa e indusio glabro.

\section{Palabras clave / Kew words: Tectariaceae, Tectaria, Tectaria dressleri, Panama}

Se han hecho varias contribuciones importantes sobre el género Tectaria en los últimos 20 años; entre ellas Jermy y Walker (1985), que basados en estudios citogenéticos describen Tectaria vivipara Jermy \& T.G. Walker y T. xbulbifera Jermy \& T.G. Walker y utilizan estos nombres para material de otros países del Neotrópico. Grayum (1987) reinterpreta el uso de tres nombres en el género Tectaria. Proctor y Evans (1989) describen una especie nueva de Tectaria de Puerto Rico. Por su parte Moran (1990) publica Tectaria acerifolia R.C. Moran, una especie presente sólo en Costa Rica y Panamá, además de Tectaria pubens R.C. Moran (Moran 1992), una especie de Sudamérica. Rojas (2001) describe seis especies nuevas de Tectaria del Neotrópico y Rojas (2004) el híbrido Tectaria x chaconiana A. Rojas, de Costa Rica.

Recientemente se encontró material de Tectaria de Panamá con características muy diferentes a las de especies conocidas y, por tanto, se describe aquí como especie nueva, después de haber revisado material de los herbarios COL, CR, F, INB, MO, PMA, UC, UNAM y US y haber consultado diferentes trabajos; entre ellos Morton (1966), Jermy \& Walker (1985), Holttum (1986), Grayum (1987), Moran (1990, 1992, 1995), Tryon \& Stolze (1991) y Rojas $(2001,2004)$.

\section{Tectaria dressleri A. Rojas, sp. nova}

A Tectaria pubenti R.C. Moran affinis, sed frondibus integribus, lamina adaxialiter pilosa, indusio glabro absimilis.

TIPO: PANAMÁ. Panamá: Altos de Pacora (La Eneida), about $16 \mathrm{~km}$ NE of Cerro Azul, 29 Apr 1973, R. Dressler 4366 (Holotipo: MO, isotipo: US). Fig. 1.

Terrestre; rizoma 3-7 mm de diám., suberecto; escamas del rizoma 4-8 x ca. $0.5 \mathrm{~mm}$, pardas, lanceoladas a linear-lanceoladas; frondas de $25-35 \mathrm{~cm}$ de largo; estípite 10-18 cm (2/5-1/2 del tamaño del fronde), pardo, pubérulo principalmente en la base y en el dorso, los pelos 0.3-1 mm; escamas del estípite similares a las del rizoma, lanceoladas a lineares; lámina 14-18 x 7.5-10.5 cm, lanceolada a deltada, simple, entera o con un pequeño par de lóbulos basales, base cordiforme, ápice acuminado, yemas prolíferas ausentes; raquis comúnmente pardo claro a pajizo, piloso, los pelos 0.5-1.5 mm de largo, patentes, pardo claro, con los tabiques intercelulares pardo oscuro; raquis, costas y venas pilosos en ambas superficies, los pelos $0.5-1.5 \mathrm{~mm}$, con 5-8 células, translúcidos, densos, con los tabiques intercelulares pardo-rojizo; tejido laminar piloso en ambas superficies, los pelos 0.5-1 $\mathrm{mm}$, medianamente densos; aréolas típicamente con nérvulos libres incluidos; soros redondos, dispuestos en (1-) 2 series entre las nervaduras laterales principales; indusio circular, unido lateralmente, pero cordado y los lóbulos traslapándose, superficie glabra.

DisTRIBUCión. Panamá; especie conocida sólo del material tipo de Altos de Pacora, 600-700 m.

Tectaria dressleri se diferencia de T. pubens R.C. Moran por lámina simple o apenas con unos leves lóbulos basales (vs. pinnada), raquis y costas igualmente pilosos en ambas superficies (vs. densamente pilosos en el envés y dispersamente pilosos o glabros en la haz), venas y tejido laminar igualmente pilosos (vs. venas más pilosas que el tejido laminar en el envés), tejido laminar piloso en la haz (vs. glabro), e indusio glabro (vs. piloso).

Esta especie se parece a T. heracleifolia (Willd.) Underw. por su lámina pequeña y deltada, pero se diferencia porque no tiene segmentos o pinnas distinguibles, sólo unos pequeños lóbulos basales, y 
por tener abundantes pelos en ambas superficies de la lámina. También se parece a T. pilosa (Fée) R.C. Moran por su pilosidad, pero la planta es más pequeña (20-30 cm vs. $35-80 \mathrm{~cm}$ ), con lámina entera (vs. pinnada).

Tectaria dressleri es conocida hasta ahora sólo por el material tipo; sin embargo, las características tan particulares de esta especie y la abundancia de material de las especies relacionadas indican que no es parte de la variabilidad de alguna otra especie.

Etimología. Esta especie es dedicada al Dr. Robert L. Dressler, reconocido orquideólogo que recolectó el material tipo.

Agradecimientos. Agradezco el apoyo de los herbarios COL, CR, F, INB, MO, PMA, UC, UNAM y US, por permitirme utilizar sus colecciones $\mathrm{y}$, en algunos casos, por el préstamo de material. A los revisores anónimos que ayudaron a mejorar este artículo. A Francisco Quesada por su excelente ilustración.

\section{LITERATURA CITADA}

Grayum, M.H. 1987. On three misunderstood neotropical species of Tectaria (Polypodiaceae: Asplenioideae). Phytologia 64: 30-35.

Holttum, R.E. 1986. Studies in the fern genera allied to Tectaria Cav. VI. A Conspectus of genera in the Old
World regarded as related to Tectaria, with descriptions of two genera. Gard. Bull. Singapore 39: 153-167.

Jermy, A.C. \& T.G. Walker. 1985. Cytotaxonomic studies of the ferns of Trinidad: 3. Descriptions of new species and hybrids and a new combination. Bull. Brit. Mus. (Nat. Hist.), Bot. 13: 251-256.

Moran, R.C. 1990. Three new species of ferns from Mesoamerica. Ann. Missouri Bot. Gard. 77: 591-592.

Moran, R.C. 1992. Five new species of ferns from the American tropics. Novon 2: 137-138.

Moran, R.C. 1995. Tectaria. In: Moran, R.C. \& R. Riba (eds.). Flora Mesoamericana. Vol. 1. Psilotaceae a Salviniaceae. Univ. Nac. Autónoma México. México D.F. p. 195-210.

Morton, C.V. 1966. The Mexican species of Tectaria. Amer. Fern J. 56: 120-137.

Proctor, G.R. 1989. Ferns of the Puerto Rico and the Virgin Islands. Mem. New York Bot. Gard. 53: 250257.

Rojas, A.F. 2001. Ocho nuevas especies y nuevos ámbitos geográficos de helechos de la familia Tectariaceae (Filicales) en el neotrópico. Rev. Biol. Trop. 49(2): 467-488.

Rojas, A.F. 2004. Un nuevo híbrido de Tectaria (Filicales: Tectariaceae) en Costa Rica. Lankesteriana 4(2): 149154.

Tryon, R.M. \& R.G. Stolze. 1991. Pteridophyta of Perú. Part IV. 17. Dryopteridaceae. Fieldiana, Bot. n.s. 27: 1-176. 


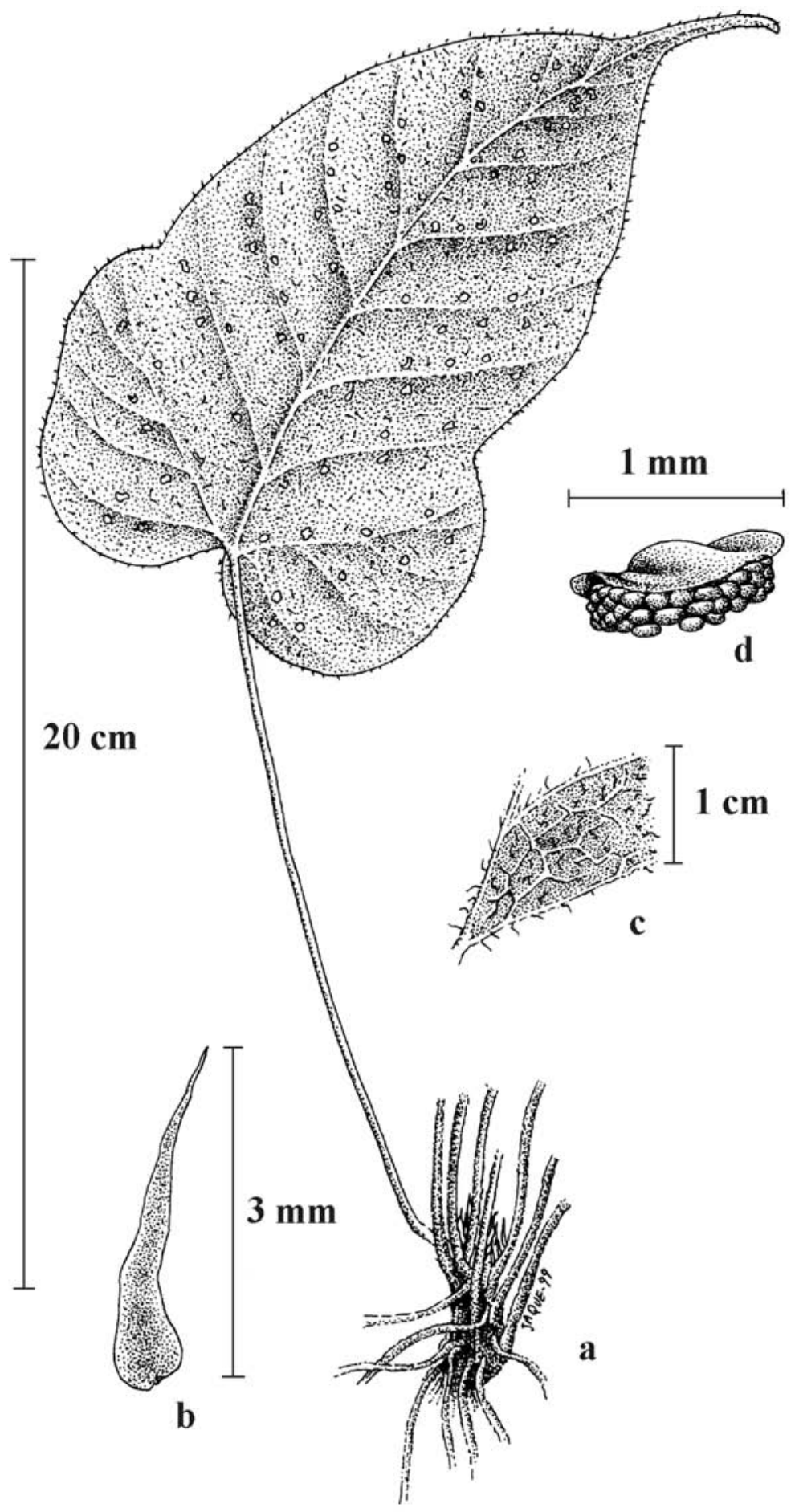

Fig. 1. Tectaria dressleri A. Rojas (R. Dressler 4366, MO). a) Hábito. b) Escama del rizoma. c) Detalle de la lámina. d) Soro. 
